\title{
$\frac{12}{125194}$ OSD
}

UCRL-ID-117952

\section{An Analytical Electron Distribution Function for Inelastic Collisions in a Uniform Gas with Time Varying Electric Field}

\author{
Manuel Garcia
}

July 21, 1994

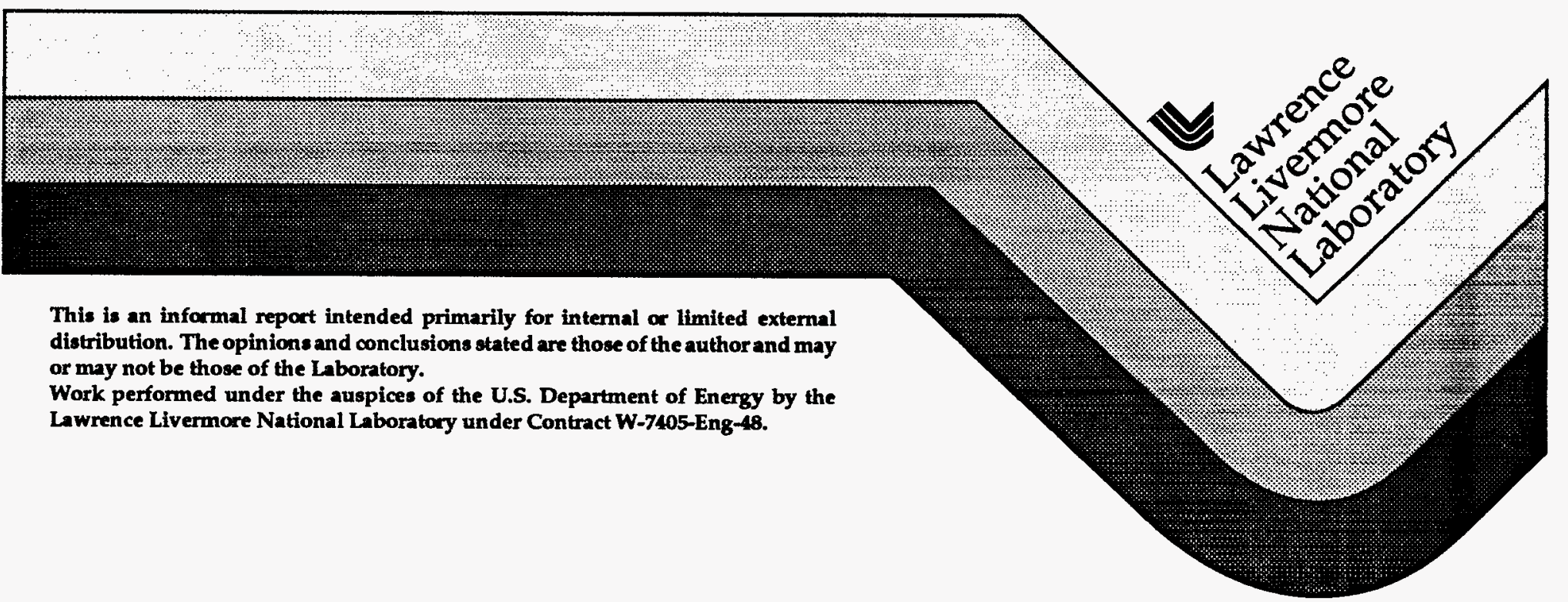

This is an informal report intended primarily for internal or limited external distribution. The opinions and conclusions stated are those of the author and may or may not be those of the Laboratory.

Work performed under the auspices of the U.S. Department of Energy by the Lawrence Livermore National Laboratory under Contract W-7405-Eng-48. 


\section{DISCLAIMER}

This document was prepared as an account of work sponsored by an agency of the United States Government. Neither the United States Government nor the University of California nor any of their employees, makes any warranty, express or implied, or assumes any legal liability or responsibility for the accuracy, completeness, or usefulness of any information, apparatus, product, or process disclosed, or represents that its use would not infringe privately owned rights. Reference herein to any specific commercial products, process, or service by trade name, trademark, manufacturer, or otherwise, does not necessarily constitute or imply its endorsement, recommendation, or favoring by the United States Government or the University of California. The views and opinions of authors expressed herein do not necessarily state or reflect those of the United States Government or the University of California, and shall not be used for advertising or product endorsenent purposes.

This report has been reproduced directly from the best available copy.

Available to DOE and DOE contractors from the Ofice of Scientific and Technical Information P.O. Box 62, Oak Ridge, TN 37831

Prices available from (615) 576-8401, FTS 626-8401

A vailable to the public from the National Technical Information Service

US. Department of Commerce 5285 Port Royal Rd. Springfield, VA 22161 


\section{DISCLAIMER}

Portions of this document may be illegible in electronic image products. Images are produced from the best available original document. 


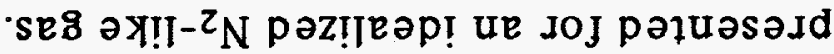

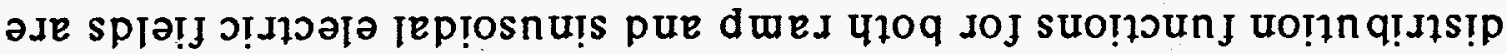

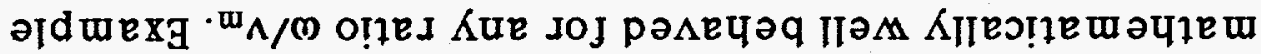

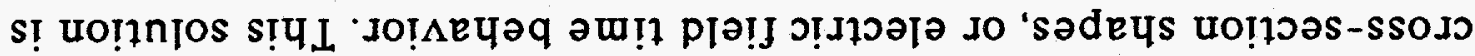

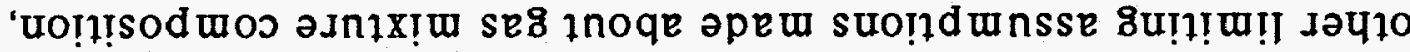

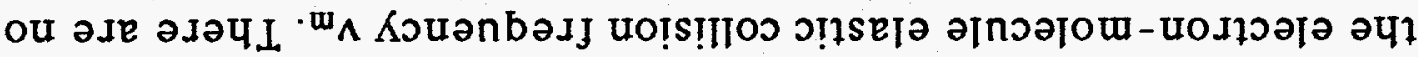

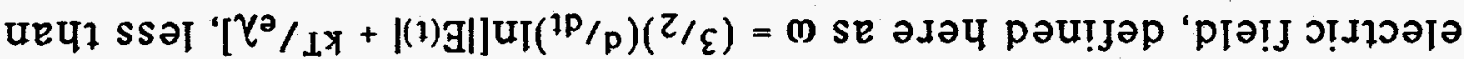

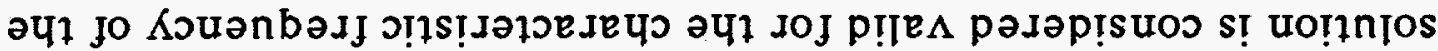

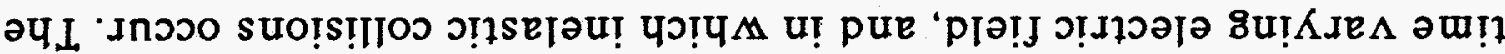

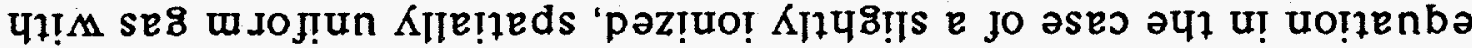

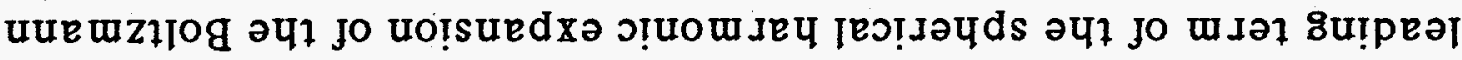

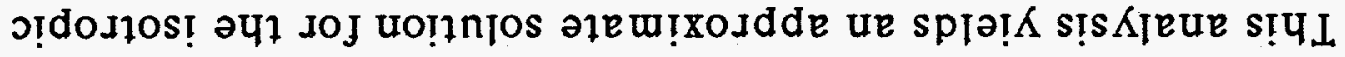

\section{L.JVYLSG}

\section{I Kin I IZ \\ eİJes IONuEN}

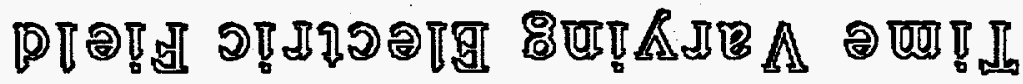

पगฐ

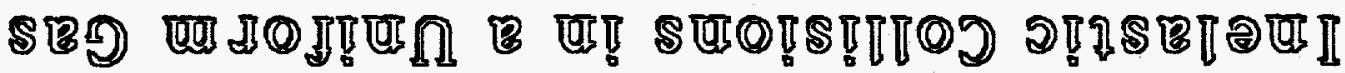

$$
\text { IOJ }
$$

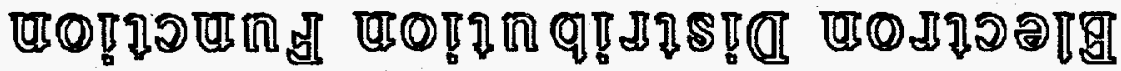

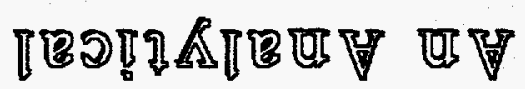


Acknowledgments:

Jim Brittingham and Ching Wang (of LLNL)

$\&$

Iben Browning and Hannes Alfvèn for a passionate perseverance in their science. 


\section{Introduction}

The desire for improved control over electric discharge phenomena in a wide variety of scientific, technological, manufacturing, and waste processing activities spurs the development of non-equilibrium, non-uniform, and time dependent models. This paper addresses the situation of a slightly ionized, spatially uniform gas with a time varying electric field, and in which inelastic collisions occur. The purpose here is to present a reasonably consistent, and reasonably accessible analytical result for the electron kinetics in a gas discharge regime of technological interest.

This paper will be structured as follows. First, the analytical result for the time dependent electron distribution function is stated. Second, a summary of the solution procedure with its attendant assumptions is given. Lastly, examples of the solution are given for an idealized nitrogen-like gas where the electric field ramps between static conditions, and then for sinusoidal behavior.

\section{Analytical Result}

The time dependent distribution function of electron energies is denoted as $f(\varepsilon, t)$, where electron kinetic energy $\varepsilon$ is expressed in units of $\mathrm{eV}$, and where the distribution function is normalized as:

$$
\int f(\varepsilon, t) \sqrt{ } \varepsilon d \varepsilon=1
$$

The function $B(\varepsilon, t)$ is defined as:

$$
B(\varepsilon, t)=-(\partial / \partial \varepsilon) \ln [f(\varepsilon, t)]
$$

and the distribution function is then given by: 


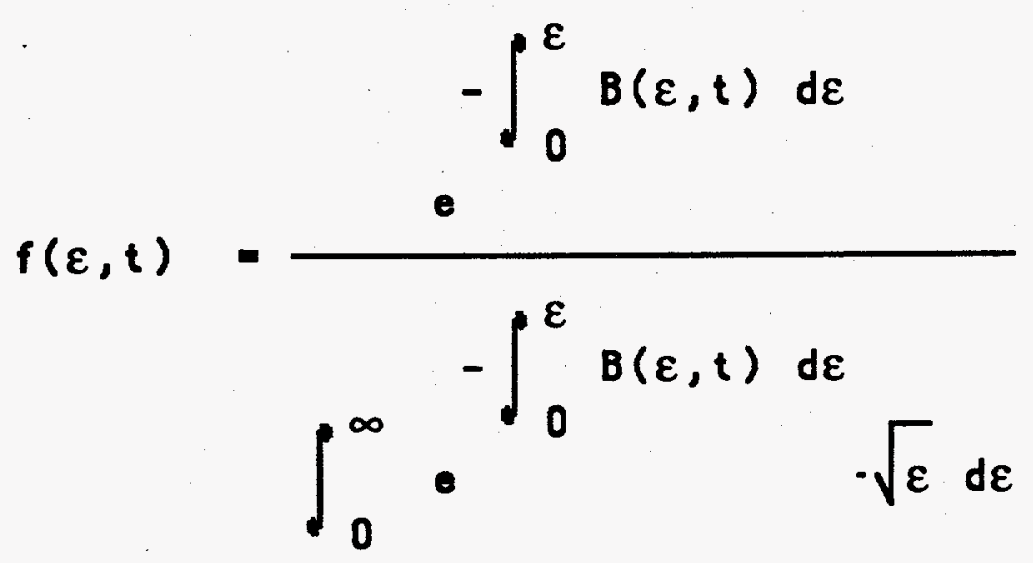

(3).

The logarithmic slope $B(\varepsilon, t)$ is given by:

$B(\varepsilon, t)=\frac{\sqrt{\left[\mu+\frac{\omega}{2 v_{m}}\right]^{2}+\left[\frac{4 \cdot Q_{i}}{\varepsilon \cdot Q_{m}}\right] \cdot\left[b+\mu \cdot \frac{k T}{e}\right]}+\left[\mu+\frac{\omega}{2 v_{m}}\right]}{2 \cdot\left[b+\mu \cdot \frac{k T}{e}\right]}$

(4).

The terms used in function $B(\varepsilon, t)$ are as follows:

$$
\begin{aligned}
& b(\varepsilon, t)=[E / N] 2 /\left(3 \varepsilon Q_{m}^{2}\right), \\
& \omega(t)=3 / 2 * 1 /[E / N] *(d / d t)[E / N], \\
& v_{m}(\varepsilon)=N * Q_{m} * \sqrt{2 e \varepsilon / m},
\end{aligned}
$$

$Q_{m}(\varepsilon)=$ electron-molecule momentum transfer cross section, 
$Q_{i}(\varepsilon)=$ electron-molecule inelastic cross section $\left(\mathrm{cm}^{2}\right)$ $\mu=2 \mathrm{~m} / \mathrm{M}$,

$$
\begin{aligned}
& m=\text { electron mass, } \\
& M=\text { molecule mass, }
\end{aligned}
$$

$\mathrm{kT} / \mathrm{e}=$ gas tem perature in $\mathrm{eV}$,

$E(t)=$ time dependent electric field $(V / c m)$ in the form:

$$
\begin{aligned}
& E(t)=|E(t)|+k T / e \cdot Q_{m}(k T / e) * N, \\
& E(t)=\text { any imposed field variation over time, }
\end{aligned}
$$

$\mathrm{N}=$ gas mixture number density $\left(\mathrm{cm}^{-3}\right)$, a constant,

For a gas mixture:

$$
\delta_{s}=\text { fractional concentration of species } \mathbf{s},
$$

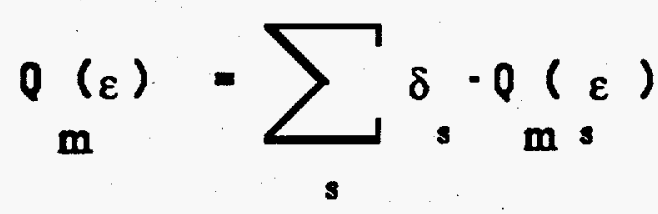

m = momentum transfer

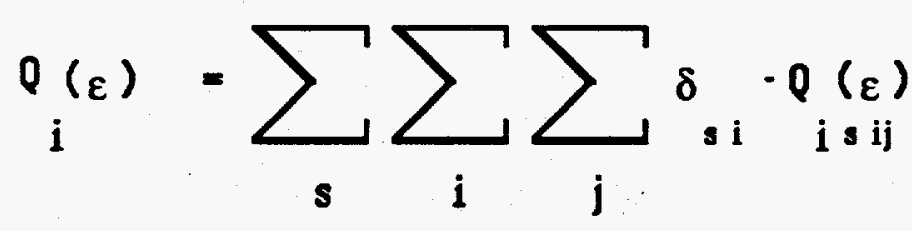

$i$ - inelastic processes with transition indices:

$i=$ index of initial energy level, $j$ - index of final energy level, 

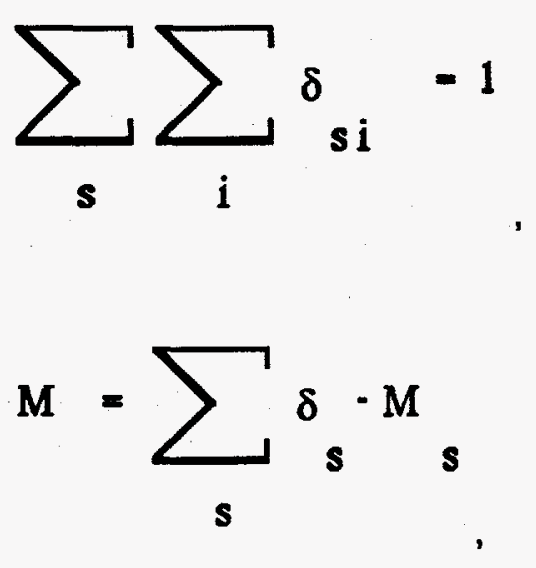

\section{Analytical Procedure}

This analysis begins with a two-term expansion of the electron velocity distribution function in a Boltzmann equation with three collisional effects: recoil and thermal agitation during elastic electron-molecule encounters, and inelastic collisions. ${ }^{1}$ The leading ter $m$ in the expansion describes the bulk heating of the electrons by the electric field in an environment dominated by collisions, while the first order term describes the net drif $t$ of this electronic swarm along the field and represents the macroscopic current.

The recoil and thermal agitation collision terms transmit a small fraction of an electron's energy to a molecule, this fraction being given by the ratio of the electron to molecule masses. The inelastic term involves the transfer of sufficient energy to initiate rotational, vibrational, electronic, dissociation, and ionization phenomena. Analytical work on time dependent inelastic electron kinetics goes back at least half a century.2,3,4,5

The spatially uniform zeroth and first order velocity distribution equations are transformed to a dependence on electron kinetic energy in units of $\mathrm{eV}$. During this change of parameters the relative velocity between electrons and molecules is ascribed entirely to electron speed. Specifically:

$$
\begin{aligned}
& \varepsilon=m v^{2} / 2 e \\
& f_{0}(\varepsilon, t)=\left[4 \pi \sqrt{2} /(m / e)^{3 / 2}\right] * f_{0}(v, t)
\end{aligned}
$$

The two equations are combined into a single one for $f_{0}$, hence that subscript is eventually dropped. This equation is divided by $\mathrm{N}$ 
and integrated over energy from 0 to $\varepsilon$. An inelastic cross section is zero below a threshold energy which is at least as large as the energy extracted from the electron during the encounter. For example, the cross section for excitation from the 0 to 1 vibrational level in $\mathrm{N}_{2}$ is zero below about $1.4 \mathrm{eV}$, while the energy transferred is about 0.3 $\mathrm{eV}$. This fact about the cross sections proves useful in the manipulation of the inelastic collision integrals. The resulting equation is:

$\sqrt{\frac{m}{2 \cdot e}} \cdot \frac{1}{N} \cdot \frac{\partial}{\partial t} \cdot \int_{0}^{\varepsilon} \sqrt{\zeta \cdot f_{0}(\zeta, t) d \zeta} \ldots$
$+-\left[\begin{array}{c}E \\ - \\ N\end{array}\right] \cdot \frac{\varepsilon}{3 \cdot Q_{m}} \cdot v_{m} \cdot e^{-v_{m} t} \cdot \int_{0}^{t} e^{v_{m} \tau} \cdot \frac{\partial f_{0}(\varepsilon, \tau)}{\partial \varepsilon} d \tau=$

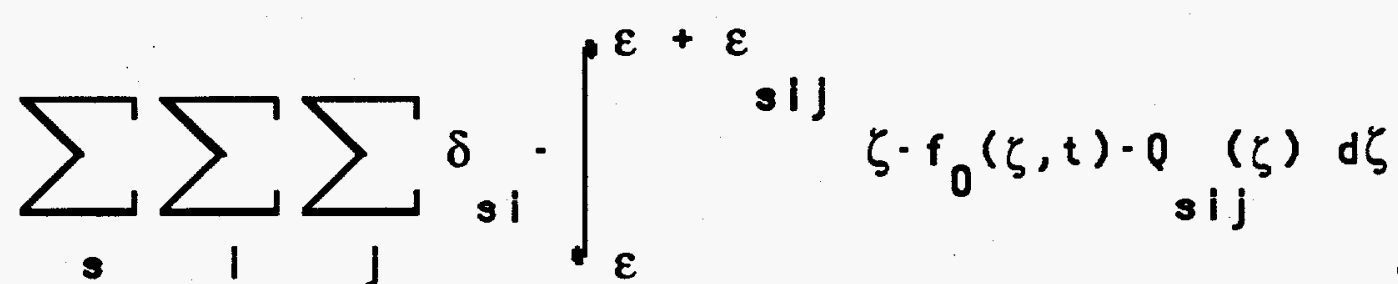
$+\left[2 \cdot \frac{m}{M}\right]^{2} \cdot O_{m} \cdot\left[f_{0}(\varepsilon, t)+\frac{k T}{e} \cdot \frac{\partial f_{0}}{\partial \varepsilon}\right]$ $+\frac{1 E}{3 M} \cdot \varepsilon \cdot e^{-V_{m}^{t}} \cdot f_{1}(\varepsilon, 0)$

The relationship between $f_{0}$ and $f_{1}$ is: 


$$
\frac{\partial f_{1}(\varepsilon, t)}{\partial t}+v_{m}(\varepsilon) \cdot f_{1}(\varepsilon, t)=-\frac{E v_{m}}{N \cdot P_{m}} \cdot \frac{\partial f_{0}(\varepsilon, t)}{\partial \varepsilon}
$$

The essence of the solution procedure employed here is to make the exponential transform from $f(\varepsilon, t)$ to $B(\varepsilon, t)$, and then to argue as in the WKB method that the equation for $B(\varepsilon, t)$ has a stationary solution. ${ }^{6} \mathrm{~B}$ is like a local inverse electron te mperature and its rate of change is assumed to be slower than the elastic collision frequency, specifically:

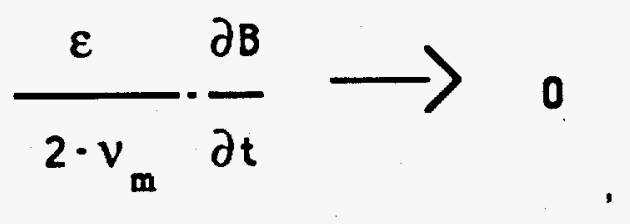

The resulting equation for $B$ includes the effect of the tem poral variation of the normalization integral of the distribution function, which is how the temporal variation of the electric field exerts its influence.

The mechanics of deriving the equation for $B(\varepsilon, t)$ involve: substituting equation ( 3 ) into equations (15) and (16) in place of $f_{0}$, and then dividing equation (15) by $f_{0}$ as defined by equation (3). A convenient label for the normalization integral is $\mathrm{C}(\mathrm{t})$. The result from equation (15) is: 


$$
\begin{aligned}
& -\sqrt{\frac{m}{2-e}} \cdot \frac{1}{N} \int_{0}^{\varepsilon} \sqrt{\zeta \cdot e^{-1}} \int_{\zeta}^{B(\eta, t) d \eta} \frac{\partial}{\partial t} \cdot\left[\int_{0}^{\zeta} B(\eta, t) d \eta\right] d \zeta \\
& \left.+\left[\begin{array}{c}
E \\
- \\
N
\end{array}\right]^{2} \cdot \frac{\varepsilon \cdot v_{m}}{3 \cdot Q_{m}} \cdot \int_{0}^{t} \frac{C(t)}{C(\tau)} e^{\left[\int_{0}^{\varepsilon}[B(\eta, t)-B(\eta, \tau)] d \eta\right.} \ldots\right] \cdot B(\varepsilon, \tau) d \tau,
\end{aligned}
$$

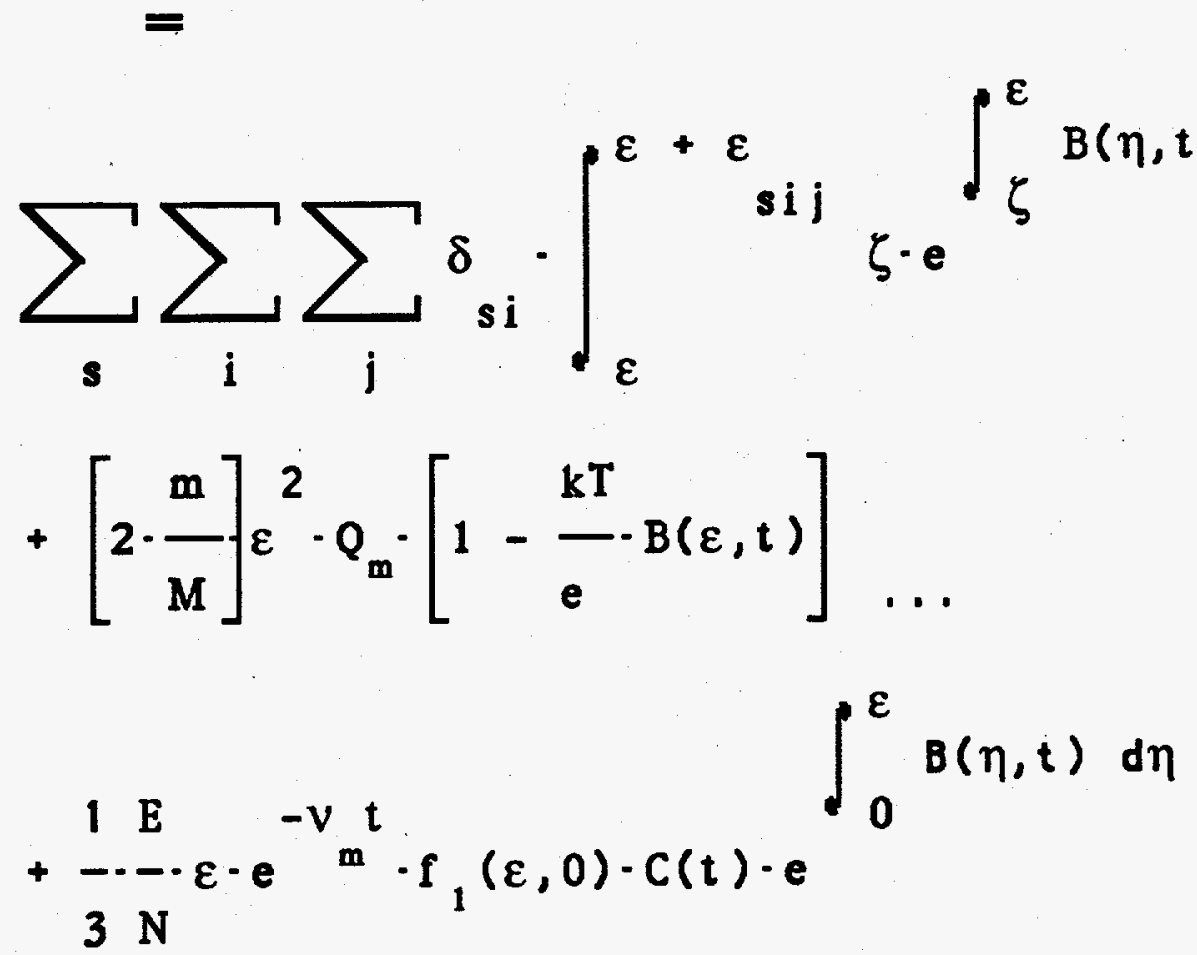

The analysis of this equation now proceeds by a sequence of approximations. The basic assumptions are: 
i) B is a weak function of $\varepsilon$,

ii) $B$ is invariant during a collision time,

iii) $C(t)$ can be approximated as:

$$
c(t) \approx \int_{0}^{\infty} e^{-\frac{\left\langle\sqrt{3 \cdot Q_{m} \cdot Q_{i}}\right\rangle}{E(t) / N}} \varepsilon
$$

The approximation used for $C(t)$ is based on an energy averaged $B(\varepsilon)$ found in an earlier analysis of equation (18) in steady state and for $\mathrm{m} / \mathrm{M}$ taken as zero. ${ }^{7}$ Assumptions (19) lead to a sequence of manipulations:

a) $\int B d \varepsilon$ is approximated as $\left(B^{*} \varepsilon\right)$,

b) the term in equation (18) which contains time derivatives is expressed as two integrals in the for $m$ of incomplete gam ma functions, and each in turn is approximated by a two point trapezoid rule,

c) the time integral term of equation (18) is simplified to:

$$
B * \int e^{-v_{m} *(t-\tau)} d \tau \text {, }
$$

as suggested by the condition expressed as equation (17), also the limit of this integral at $t=0$ identically cancels the $f_{1}$ term in equation (18),

d) from (19):

$$
\partial \ln [C(t)] / \partial t=(3 / 2) \partial \ln [E(t) / N] / \partial t
$$

e) the inelastic collision integrals in equation (18) are approximated by $\varepsilon{ }^{*} Q_{i} / B(\varepsilon, t)$, as was done in an earlier analysis. ${ }^{7}$ The resulting equation for $B(\varepsilon, t)$ is: 


$$
\begin{aligned}
& -\sqrt{\frac{m}{2 \cdot e}} \cdot \frac{\varepsilon^{2}}{2 \cdot N} \cdot \frac{\partial B(\varepsilon, t)}{\partial t}-\sqrt{\frac{m}{2 \cdot e}} \cdot \frac{\varepsilon^{2}}{2 \cdot N} \cdot \frac{3 d}{2 d t} \ln \left[\begin{array}{c}
E \\
- \\
N
\end{array} \ldots\right. \\
& +\left[\begin{array}{c}
E \\
-
\end{array}\right]^{2} \cdot \frac{\varepsilon}{3 \cdot Q_{m}} \cdot B(\varepsilon, t)= \\
& \frac{\varepsilon \cdot Q_{i}}{B(\varepsilon, t)}+\left[2 \cdot \frac{m}{M}\right]^{2}-Q_{m} \cdot\left[1-\frac{k T}{e} \cdot B(\varepsilon, t)\right]
\end{aligned}
$$

This is rearranged to:

$$
\begin{aligned}
\frac{\varepsilon}{2 \cdot v_{m}} \cdot \frac{\partial B(\varepsilon, t)}{\partial t}= & \left.\frac{\left[\begin{array}{l}
E \\
- \\
N
\end{array}{ }^{2}\right.}{3 \cdot \varepsilon \cdot Q_{m}^{2}}+2 \cdot \frac{m k T}{M e}\right] \cdot B(\varepsilon, t) \\
& -\frac{Q_{i}}{Q_{m} \cdot \varepsilon} \cdot \frac{1}{B(\varepsilon, t)}-\left[2 \cdot \frac{m}{M}+\frac{\omega(t)}{2 v_{m}}\right]
\end{aligned}
$$

Equation (4) results from applying condition (17) to equation (21). 
Limiting cases of $B(\varepsilon, t)$ are:
a) $\omega \rightarrow+\infty, B \rightarrow+\infty, \quad$ (infinitely steep $\mathrm{f}$ ),
b) $\omega \rightarrow-\infty, B \rightarrow 0, \quad$ (flat $f$ ),
c) $\omega=0, \quad$ DC: (table below)

$$
\mu=0 \quad Q_{i}=0 \quad E / N=0
$$

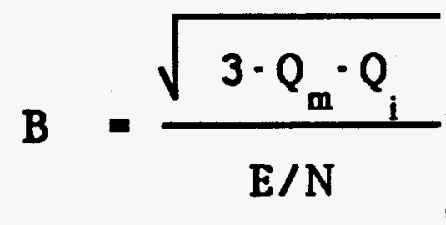

massless,

$B=\frac{\mu}{b+\mu \cdot \frac{k T}{e}, \text { elastic, }}$

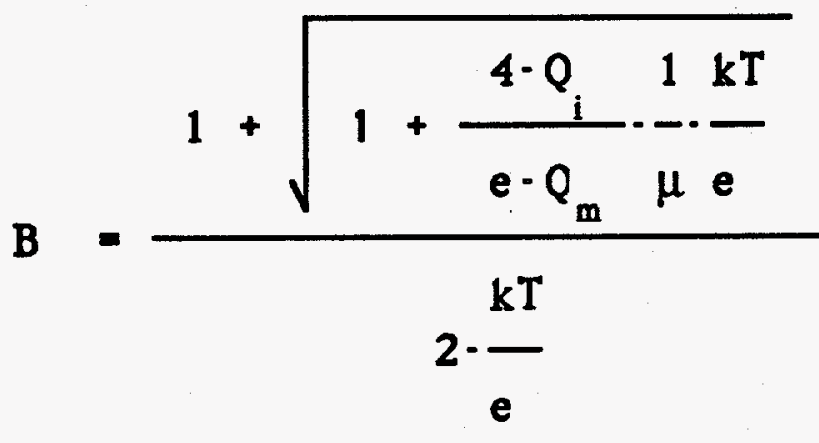

, thermal,

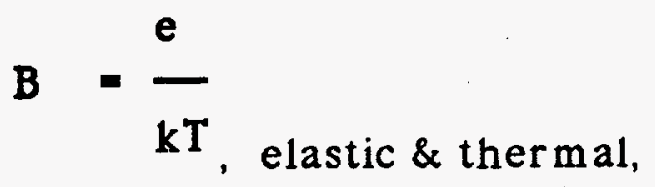

$\sqrt{ }$. 
Examples in a Model Gas

Examples are shown for a model gas with molecular weight $\mathrm{Z}=29$ (like air), a constant $\mathrm{Q}_{\mathrm{m}}=10^{-15} \mathrm{~cm}^{2}$, at temperature $\mathrm{T}=300^{\circ} \mathrm{K}$, and at number density $\mathrm{N}=3.54 * 10^{16} \mathrm{~cm}^{-3}$ ( 1 Torr). An inelastic cross section similar to vibrational excitation in $\mathrm{N}_{2}$ and with a peak of $\mathrm{Q}_{\mathrm{i}}(1.7 \mathrm{eV})=3^{*} 10^{16} \mathrm{~cm}^{2}$ was chosen and is shown below.

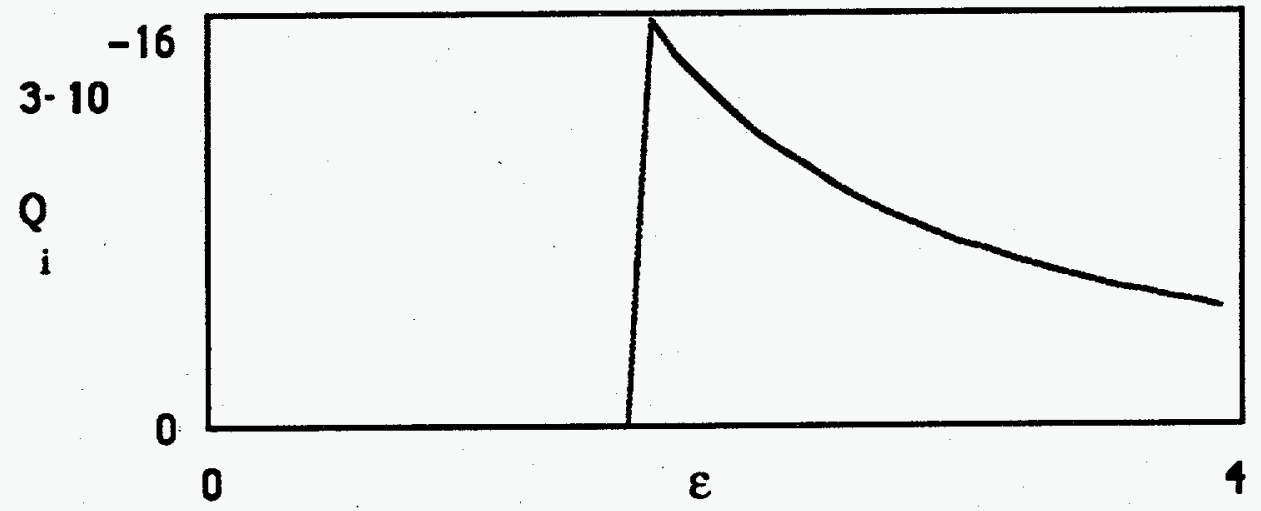

Figure 1: Model Inelastic Cross Section

The first three examples are E/ $\mathrm{N}$ ramps (linear) up to 100 Townsends $\left(1 \mathrm{Td}=10^{-17}\right.$ Volts $\left.-\mathrm{cm}^{2}\right)$, particulars are noted by each figure (Figures 2 through 5 ).

The second three examples are for field collapse (linear) from an initially steady $100 \mathrm{Td}$ (Figures 6 through 12 ). 


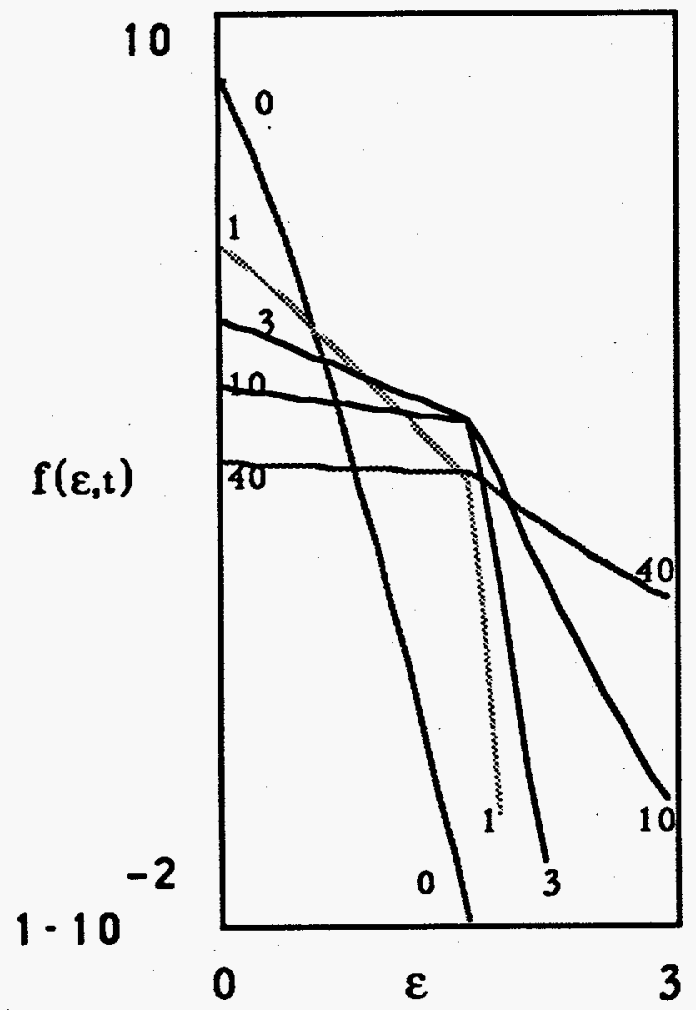

$\operatorname{LOG}[f(\varepsilon, \mathrm{t})]$ vs. $\varepsilon(e V)$

$\mathrm{E} / \mathrm{N}=0$ to $100 \mathrm{Td}$ in $20 \mu \mathrm{s}$.

labeled by time step.

$\Delta \mathrm{t}=0.625 \mu \mathrm{s}$,

210 collisons $/ \Delta t$, $\omega / v<.009$

Figure 2: $100 \mathrm{Td}, 20 \mu \mathrm{s}$ ramp

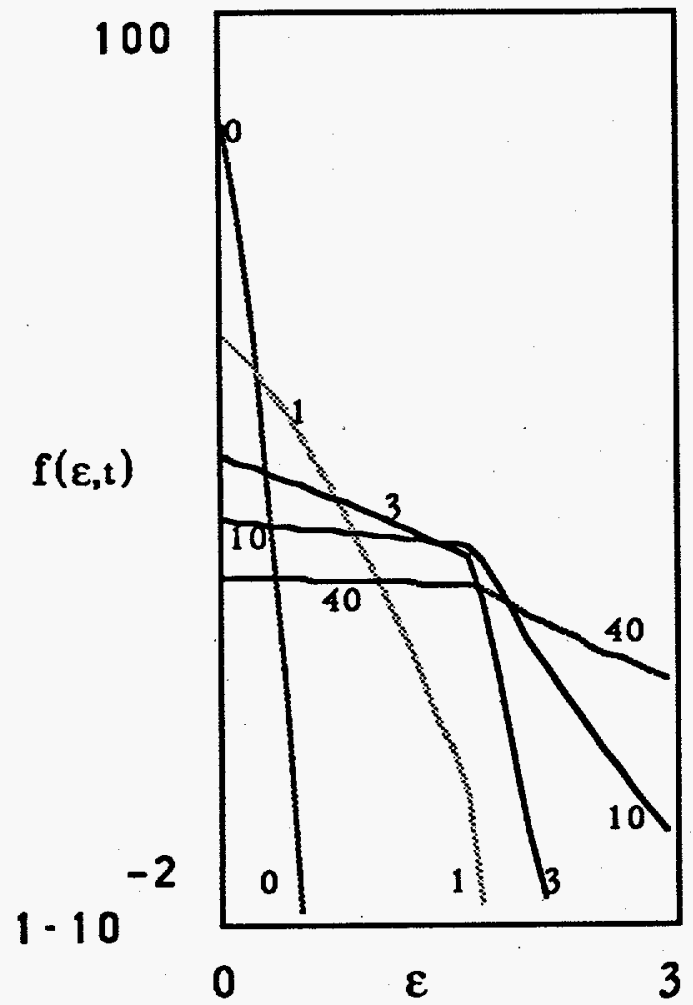

$\operatorname{LOG}[f(\varepsilon, t)]$ vs. $\varepsilon(e V)$,

$E / N=0$ to $100 \mathrm{Td}$ in $2 \mu \mathrm{s}$,

labeled by time step. $\Delta \mathrm{t}=62.5 \mathrm{~ns}$,

21 collisions $/ \Delta t$, $\omega / v<.09$

Figure 3: $100 \mathrm{Td}, 2 \mu \mathrm{s}$ ramp 


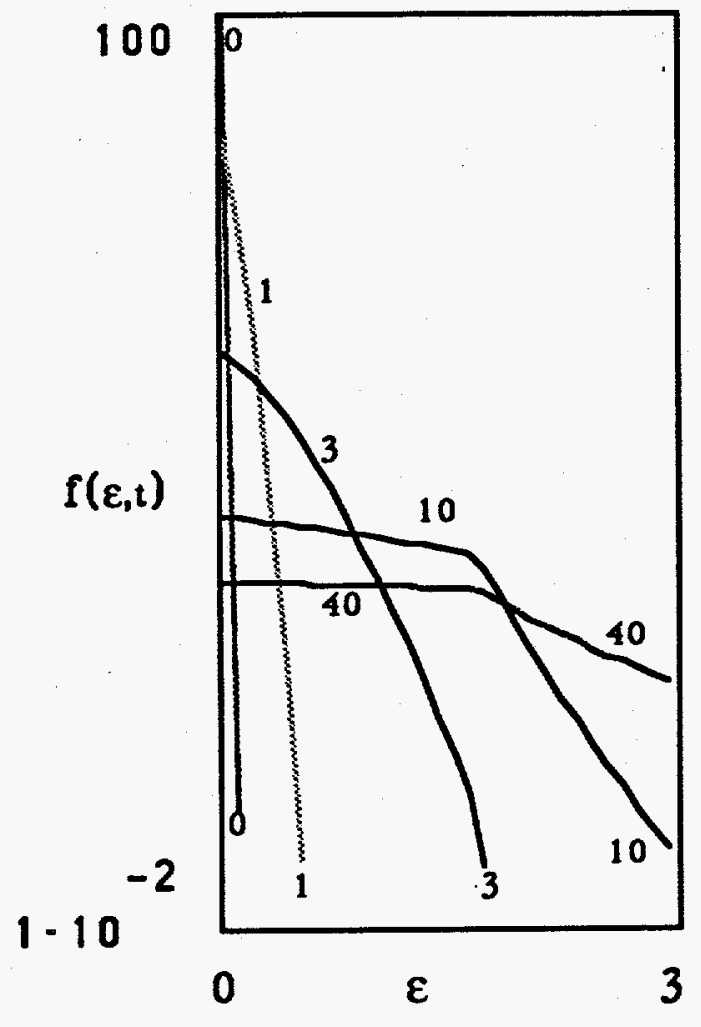

$\operatorname{LOG}[f(\varepsilon, t)]$ vs. $\varepsilon(e V)$,

$\mathrm{E} / \mathrm{N}=0$ to $100 \mathrm{Td}$ in $0.2 \mu \mathrm{s}$, labeled by time step, $\Delta \mathrm{t}=6.25 \mathrm{~ns}$, 2 collisions $/ \Delta t$, $\omega / v<0.9$

Figure 4: $100 \mathrm{Td}, 0.2 \mu \mathrm{s}$ ramp

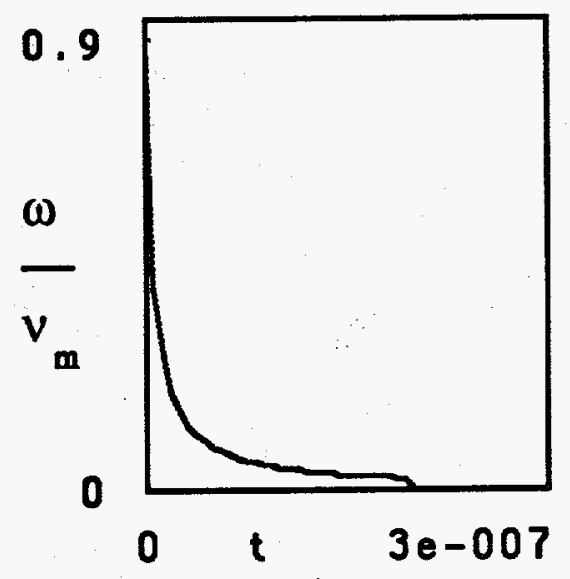

Figure 5: $\omega / v_{m}$ for example of Figure 4 


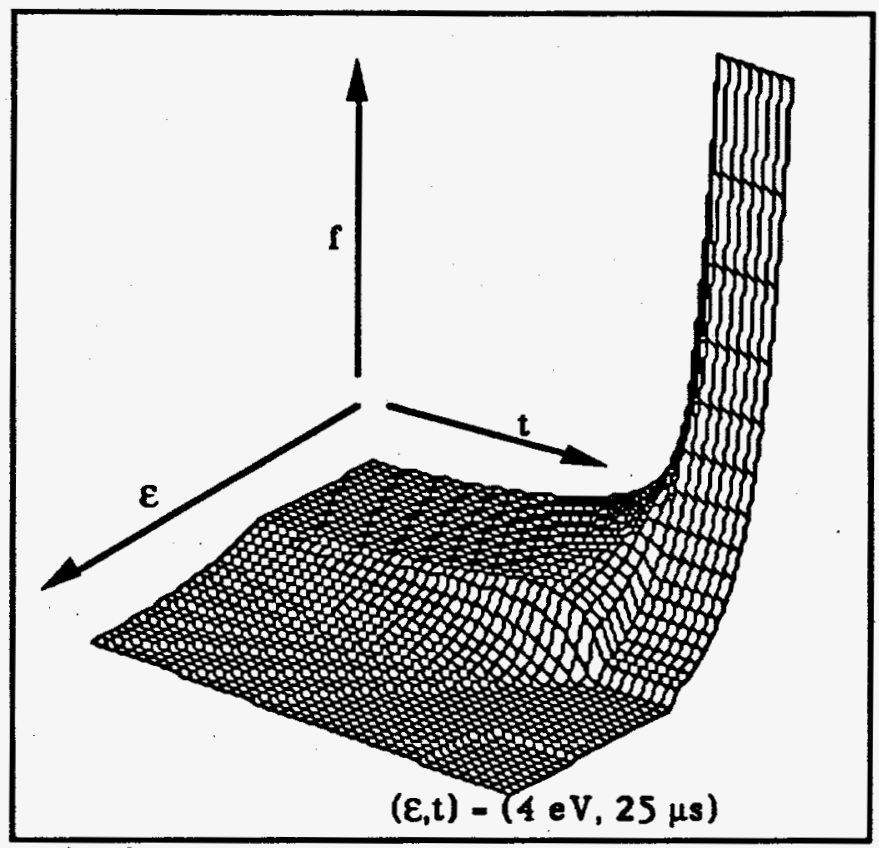

$f(\varepsilon, t)$

Figure 6: Field Collapse from $100 \mathrm{Td}$ in $20 \mu \mathrm{s}$

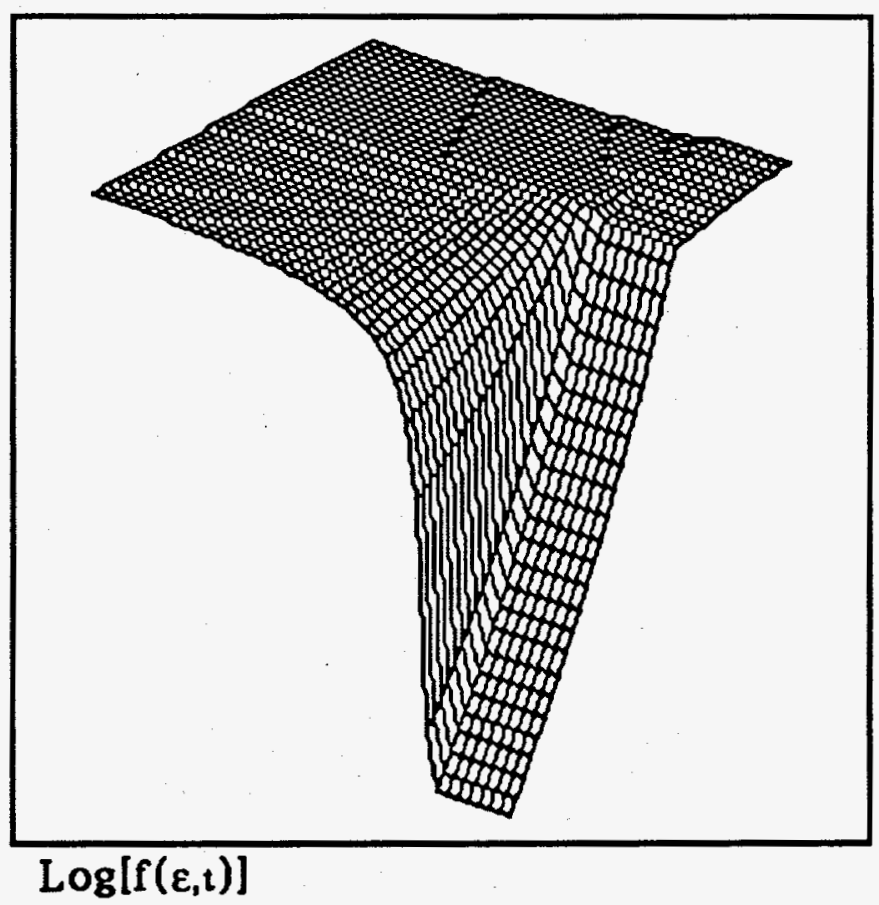

Figure 7: Log representation of Figure 6 


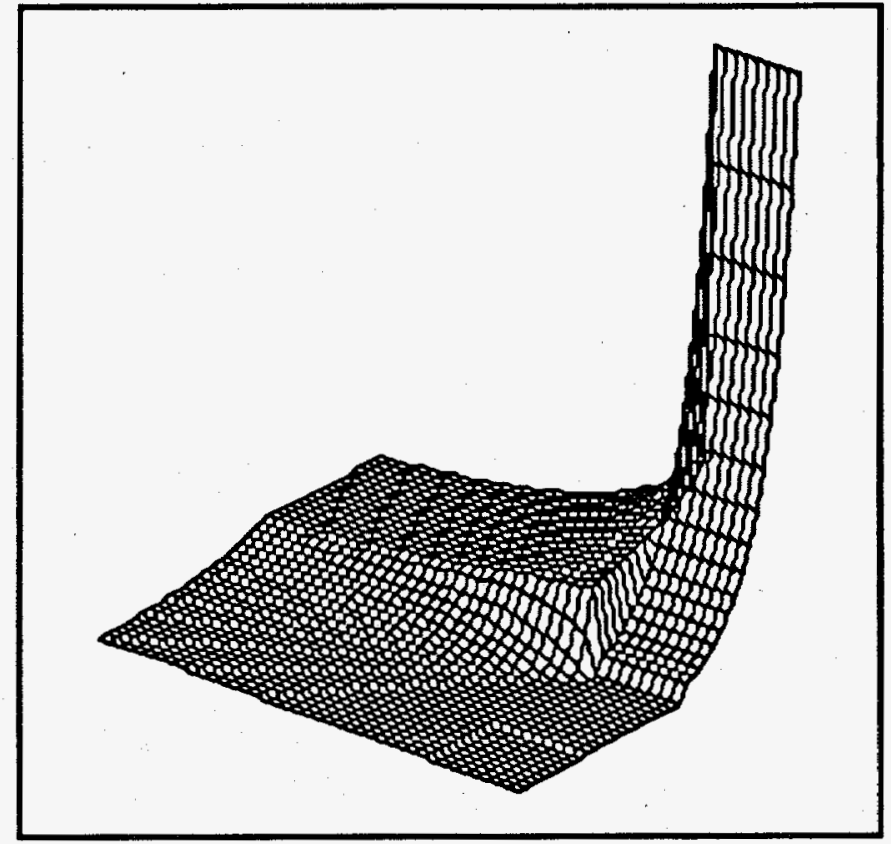

$f(\varepsilon, t)$

Figure 8: Field Collapse from $100 \mathrm{Td}$ in $2 \mu \mathrm{s}$ $(\varepsilon, t)$ from $(0,0)$ to $(4 \mathrm{eV}, 2.5 \mu \mathrm{s})$,

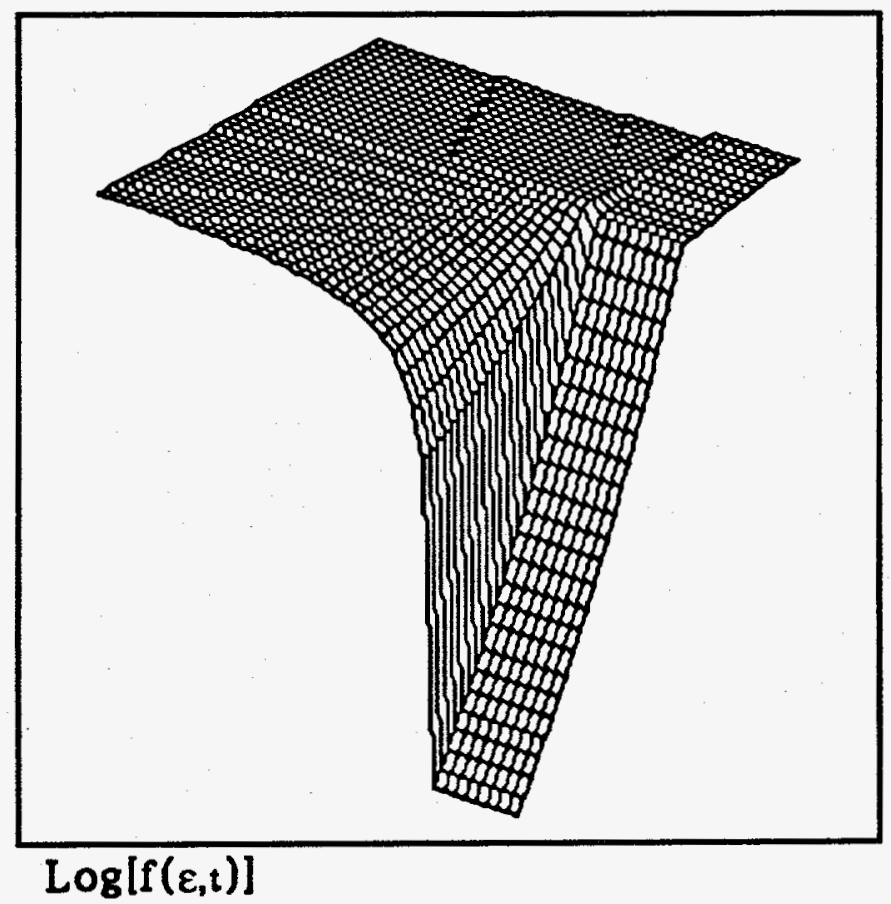

Figure 9: Log representation of Figure 8 


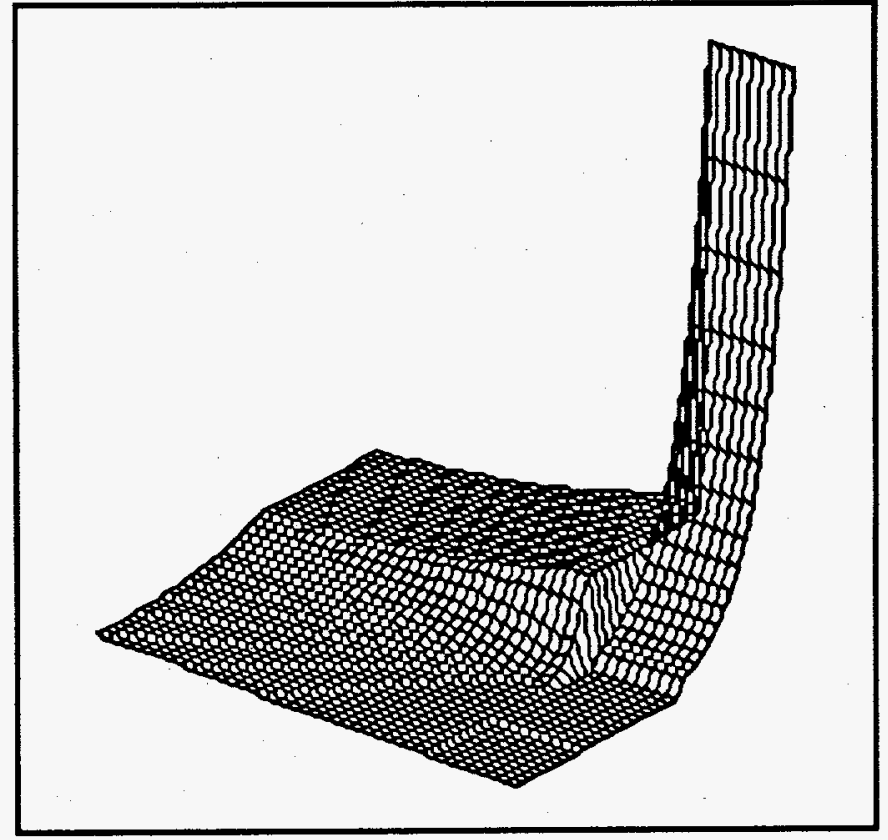

$f(\varepsilon, t)$

Figure 10: Field Collapse from $100 \mathrm{Td}$ in $0.2 \mu \mathrm{s}$ $(\varepsilon, t)$ from $(0,0)$ to $(4 \mathrm{eV}, 0.25 \mu \mathrm{s})$

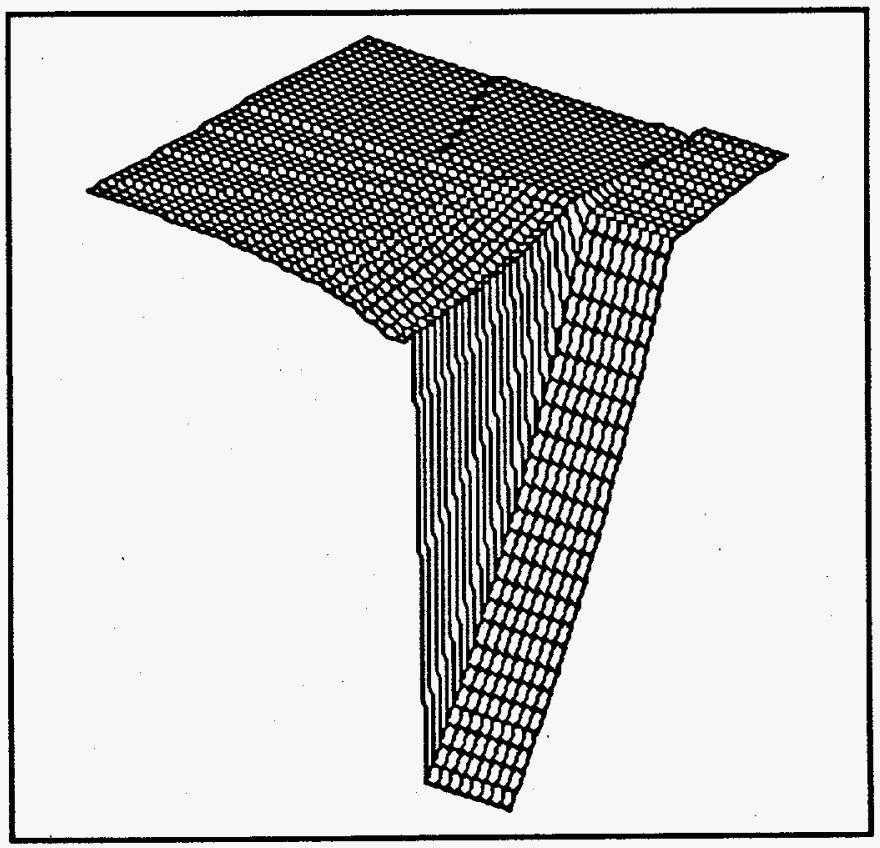

$\log [f(\varepsilon, t)]$

Figure 11: Log representation of Figure 10 


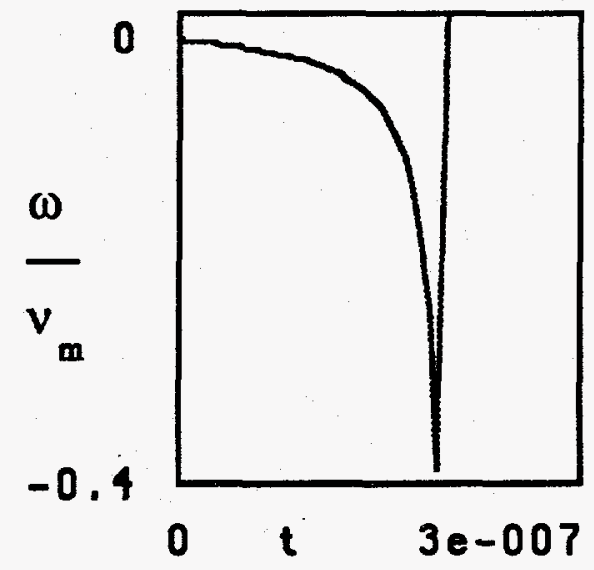

Figure 12: $\omega / v_{m}$ for example of Figure 10

The last two examples are for $\mathrm{E} / \mathrm{N}$ a sine wave with phase angle $\phi$ after $t=0 . E / N$ prior to $t=0$ is steady at $100^{*} \sin (\phi) \mathrm{Td}$. These examples have $\phi=\pi / 4$. Figures 13 through 18 show these cases. 


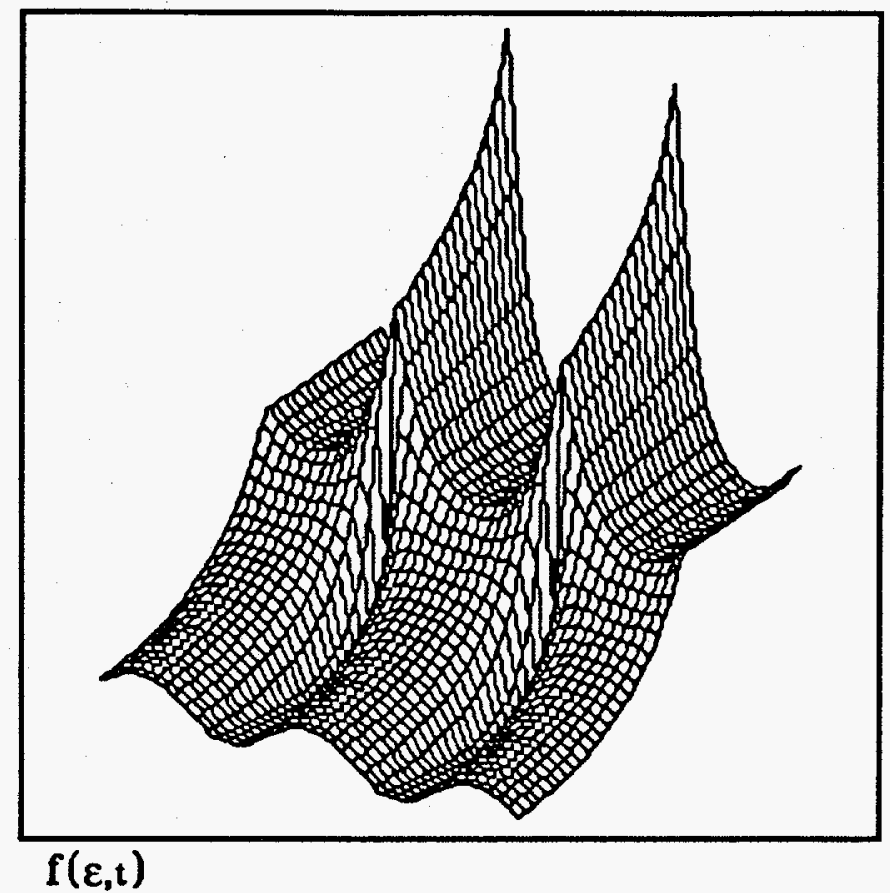

Figure 13: $100 \mathrm{Td}, 50 \mathrm{kHz}$ sine wave to $(\varepsilon, \mathrm{t})=(4 \mathrm{eV}, 25 \mu \mathrm{s})$

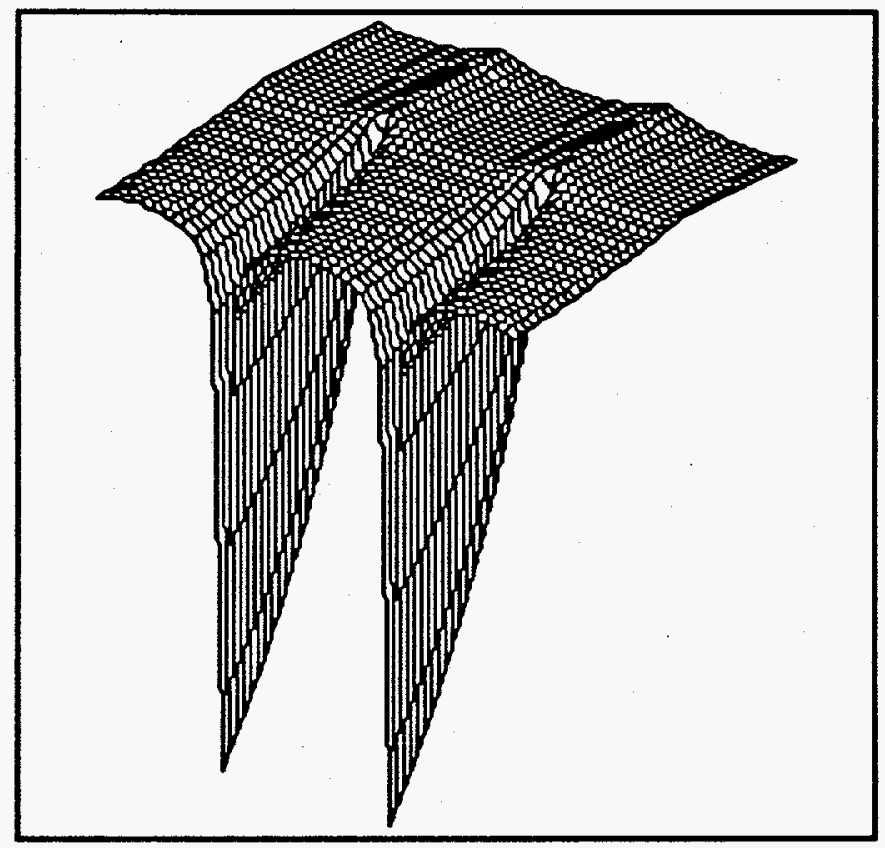

$\log [f(\varepsilon, t)]$

Figure 14: Log representation of Figure 13 


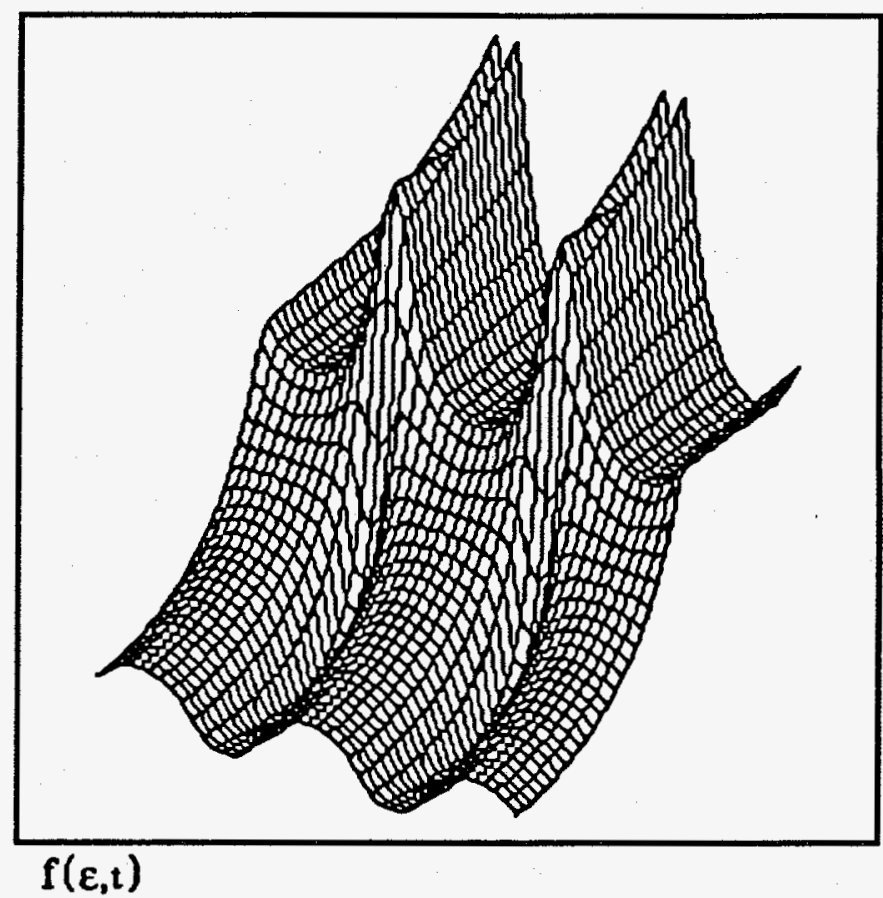

Figure 15: $100 \mathrm{Td}, 500 \mathrm{kHz}$ sine to $(\varepsilon, \mathrm{t})=(4 \mathrm{eV}, 2.5 \mu \mathrm{s})$

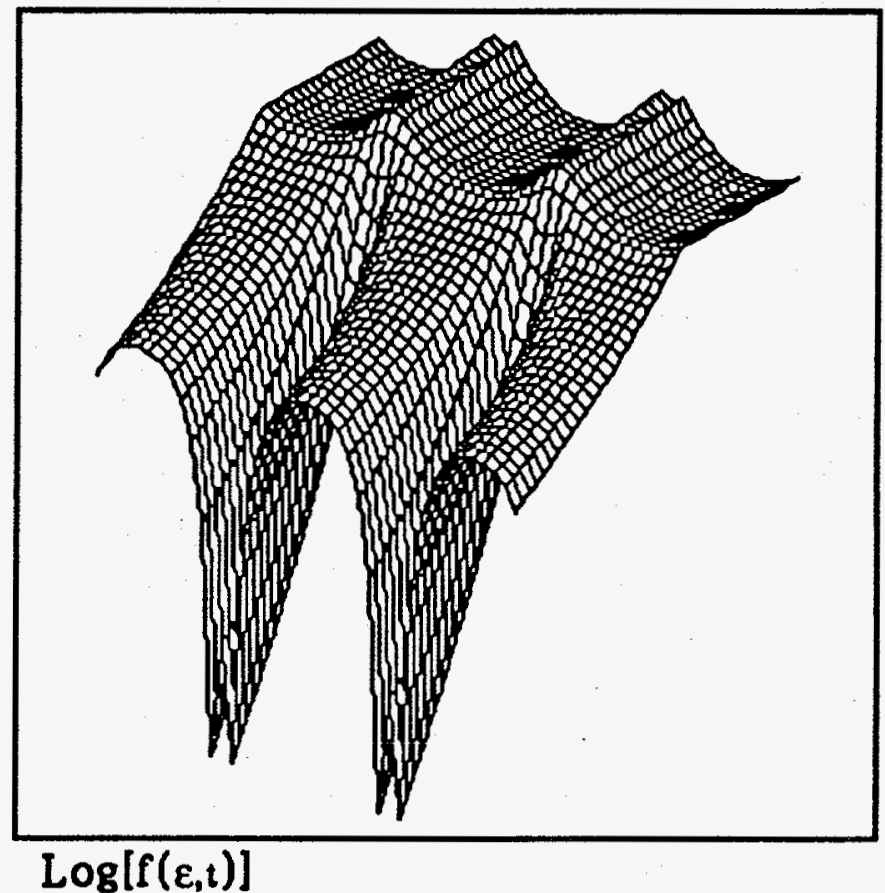

Figure 16: Log representation of Figure 15 


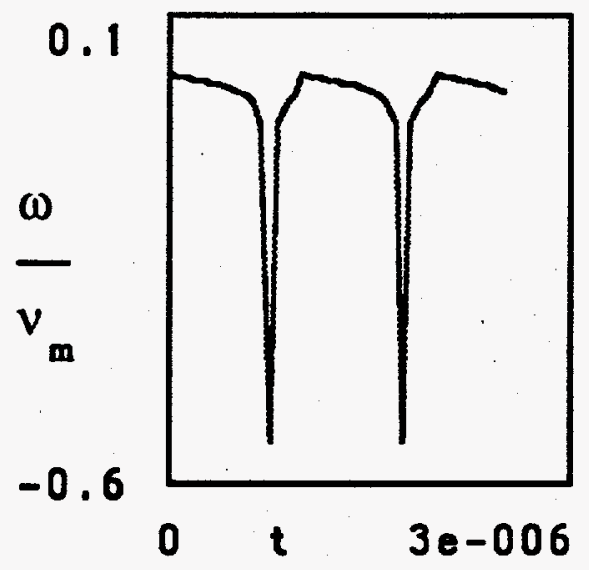

Figure 17: $\omega / v_{m}$ for example of Figure 15

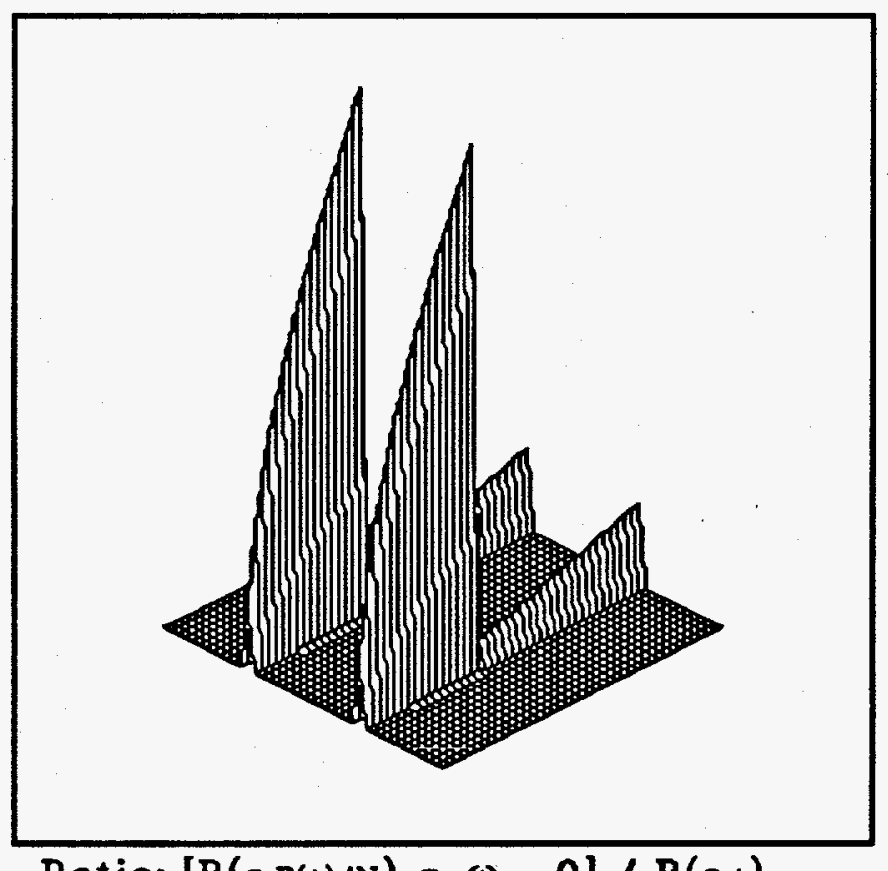

Figure 18: Ratio of $B(\varepsilon, t)$ with $\omega$ set to zero, to actual $B(\varepsilon, t)$ for example of Figure 15

[ratio $=1$ at rectangular base, ridges along high $\omega / v_{\mathrm{m}}$ ]

The microstructure developing along the node lines in the 500 $\mathrm{kHz}$ example is a mathematical artifact due to the comparable magnitudes of $\omega$ and $v_{m}$ at those locations. 


\section{Conclusions}

The function $B(\varepsilon, t)$ shown as equation (4) is presented as the logarithmic slope in energy of the electron distribution function in the case of a slightly ionized, uniform gas with both inelastic collisions, and time varying electric field. This function was derived from the Boltzmann equation through a sequence of approximations, and its validity relies on the condition $\left|\omega / v_{m}\right|<1$.

In this analysis the frequency function $\omega(t)$, defined in equation (6) on the basis of the electric field as shown in equation (11), encapsulates the purely temporal effects of $E(t)$ on the electron distribution. In addition, the instantaneous magnitude of $\mathrm{E} / \mathrm{N}$ also has an impact on the electron distribution. Figure 18 clearly shows how a time dependent solution can be quite different from a sequence of static solutions each at the instantaneous $E(t) / N$.

The model $B(\varepsilon, t)$ has physically reasonable limiting behavior, and the case of massless electrons in a static field was favorably compared to published calculations and data for a variety of gases in a previous work. ${ }^{7}$ Any approximate analysis such as this one strives to find an appropriate balance between a convenient and widely applicable result on the one hand, and accuracy on the other. Quantifying the degree to which this model approaches that $b$ alance is left to future work.

\section{Acknowledgments}

I am grateful for the interest of Dr. Yan-Ming Li of Osram Sylvania, Inc., and Drs. Britton Chang and Kenneth Sale of LLNL. 


\section{References}

1) B. E. Cherrington, Gaseous Electronics and Gas Lasers, Pergammon Press, 1979.

2) T. Holstein, "Energy Distribution of Electrons in High Frequency Gas Discharges," Physical Review, Vol. 70, No. 5 \& 6, Sept. 1946.

3) W. P. Allis, "Motion of Ions and Electrons," Handbuch der Physik, Vol. 21, 1956, pages 383-444.

4) L. M. Kovrizhnykh, "Effect of Inelastic Collisions on the Velocity Distribution of Electrons," Soviet Physics JETP, Vol. 37(10), No. 2, Feb. 1960, pages 347-353.

5) B. Sherman, "The Difference-Differential Equation of Electron Energy Distribution in a Gas," Journal of Mathematical Analysis and Applications, Vol. 1, 1960, pages 342-354.

6) I am grateful to Dr. Britton Chang of LLNL for his suggestions on this point.

7) M. Garcia, B. Chang, "Analytical Boltzmann Moments for Electrons in $\mathrm{N}_{2}-\mathrm{O}_{2}-\mathrm{H}_{2} \mathrm{O}$ Gas Mixtures," LLNL UCRL-ID-117124, presented at the IEEE International Conference on Plasma Science at Santa Fe, NM on 6 - 8 June 1994. 